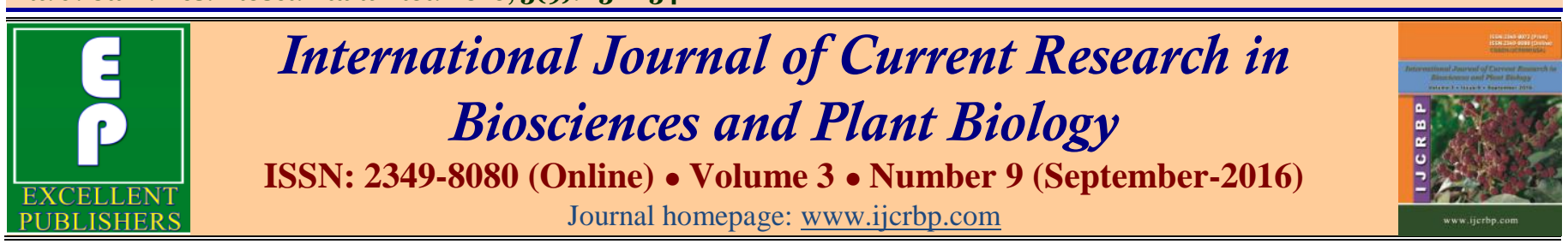

\title{
Study on Applicability of Sucrose Ester in Tissue Culture Media
}

\author{
Shubhangi Salokhe* \\ Professor, Symbiosis International University, Pune - 412115, Maharashtra, India \\ *Corresponding author.
}

\begin{abstract}
A bstract
The main purpose of this study was to find out applicability of sucrose ester in tissue culture media. Sucrose ester is classified as an emulsifier and it is usually used to improve texture, aeration, protein protection and sugar crystallization. SEs is used in many applications including bakery, confectionery, cereals, dairy, ice cream and sauces. Murashige and Skoog medium supplemented with BAP $(3 \mathrm{mg} / \mathrm{l})$ and IAA (0.5 $\mathrm{mg} / \mathrm{l}$ ) was used for tissue culture of gerbera. The nutrient mediums were supplemented with different concentrations of sucrose esters (0 to $0.5 \%)$. Shoot formation was highly influenced by concentrations of sucrose ester in medium. Among different concentrations for shoot multiplication, best performance was showed on medium supplemented with $0.025 \%$ sucrose ester. Average number of shoots per explants was higher on this medium (9.58 \pm ) with average height of longest shoot $5.05 \pm 0.02$. However, the number of shoots and height of shoot was significantly reduced when SE concentration in media was further increased ( 0.05 to $0.5 \%)$. This indicates that we can use sucrose ester in tissue culture media for improving growth of tissue cultured plantlets (number of shoots and height of shoots) and upper limit for use of SE in tissue culture media is $0.025 \%$.
\end{abstract}

\author{
Article Info \\ Accepted: 30 August 2016 \\ Available Online: 06 September 2016
}

\section{Keywords}

Gerbera

Tissue culture

Nutrient media

Sucrose ester

\section{Introduction}

Gerbera (Gerbera jamesonii) belongs to sunflower family Asteraceae and is one of the most popular ornamental flowers worldwide. It is one of the top ten traded cut flowers. It is used as a decorative garden plant, container plant, or mostly as cut flowers. Gerbera can be propagated by both sexual and asexual methods. The technique of plant tissue culture may play a key role in the "Second Green Revolution" in which biotechnology and gene modification are being used to improve crop yield and quality. Plant tissue culture is being widely accepted for its potentials in mass multiplication and preservation of elite plants. A tissue-culture technique in which propagules are cloned from tissue taken from a single plant is known as micro-propagation. Micropropagation of gerbera is being used in many countries from a range of explants (Huang and Chu, 1985; Aswath and Choudhary, 2002; Tyagi and Kothari, 2004; Aswath and Wazneen, 2004; Altaf et al., 2009; Aktar et al., 2012).

The nutrient medium is important for successful tissue culture. One of the first decisions that must be made when developing a tissue culture system is what medium to use. Nutrient media for plant tissue culture are designed to allow plant tissues to be maintained in a totally artificial environment. Many different tissue culture media have been developed, but only a few have found wide-spread use, e.g. MS (Murashige and Skoog, 1962). SH (Shenck and Hildebrandt), and Gamborg's B5. Media consist of many components; there are a huge number of permutations of substances and concentrations to test to compose an ideal medium for a particular plant 
species and genotype. Generally Murashige and Skoog medium are used for micropropagation.

Sucrose esters (SE) are obtained by esterifying sucrose with edible fatty acids from palm oil. This enables them to be used as emulsifiers in virtually all food products. Sucrose ester is classified as an emulsifier but it is usually also used to improve texture, aeration, protein protection and sugar crystallization. In modernist cuisine, sucrose ester is used to make airs and froths such as milk foams and foamy butter sauce. SEs also generates a finer texture in bakery products, stabilizes dairy and sauces and improves the texture of ice creams and mousses. SE is nontoxic, tasteless, and odorless and is digested to sucrose and FA. They are commonly used to improve the texture in low fat alternatives (Anarjan and Tan, 2013; Cristian et al., 2009; Kis et al., 2010).

Sucrose esters are used in many applications including bakery, confectionery, cereals, dairy, ice cream and sauces. They are used as emulsifiers in a wide variety of food products. They can: boost other emulsifiers; improve the solubility of flavors and fats in food products; enhance the mouth feel provided by fat in lowfat liquids; give stability and improved texture in dairy, ice cream, mousse or sauces; prevent proteins from browning; delay staling of starches; prevent fat bloom in chocolate; accelerate crystallization in fine-grained sugar confectionery; yield a finer crumb and softer texture in baked foods (Plat and Linhardt, 2001; Zeng et al., 2013; Masoud et al., 2012; Eid et al., 2015). In the present study, experiments were conducted to investigate effect sucrose ester (in nutrient media)on growth of tissue cultured Gerbera. The effect of various concentrations of sucrose ester on the initiation and multiplication of tissue cultured gerbera were examined.

\section{Materials and methods}

Initially gerbera plants were grown in the green house under controlled condition to obtain explants for tissue culture of gerbera. The shoot tips as explants from the greenhouse grown gerbera plants were taken. Explants were collected and washed in running tap water. The explants were surface sterilized with teepol for $20 \mathrm{~min}$ and with $0.1 \%$ bavistin for $30 \mathrm{~min}$. Explants were treated with $0.1 \% \mathrm{HgCl}_{2}$ for $2-3$ min under laminar flow, rinsed with double distilled water for 4-5 times and cultured on MS medium (Murashige and Skoog, 1962).

The nutrient media chosen for these studies were Murashige and Skoog's (1962) medium. MS media supplemented with BAP $(3 \mathrm{mg} / \mathrm{l})$ and IAA $(0.5 \mathrm{mg} / \mathrm{l})$ was used as a basic medium for tissue culture of gerbera. The media were supplemented with different concentrations of sucrose esters ( 0 to $0.5 \%)$. It was supplemented with $25 \mathrm{gm} / \mathrm{l}$ of sucrose and solidified with $8 \mathrm{gm} / \mathrm{l}$ of agar. The $\mathrm{pH}$ of medium was adjusted to 5.6-5.8 before autoclaving and for gelling $0.8 \%$ agar was added. Explants cultured without sucrose ester $(0 \%)$ served as the control.

Actively growing shoots were collected from 3-4months old gerbera plants grown under controlled condition in green house. The shoots were then washed with soap water for about 2-3 minutes followed by several changes of water. The plant segment was then thoroughly rinsed in $70 \%$ ethanol for 1minute. Disinfection was done by treating with sodium hypo-chloride solution for 10-15 minutes. The smell of chlorine was removed by 3-4 washings of sterile water under aseptic condition. The isolation of shoot apex meristem is done under laminar flow. The explants were then placed aseptically on modified medium for multiplication. Each experiment had seven treatments and for every treatment, 10 bottles were inoculated. The experiment was repeated three times. Observations were recorded on the number of shoots per explant and height of longest shoot.

\section{Results and discussion}

Number of shoots produced per explants and height of longest shoot on MS medium supplemented with different concentrations of sucrose ester after 8 weeks in culture were measured. Different concentrations of sucrose ester were evaluated.

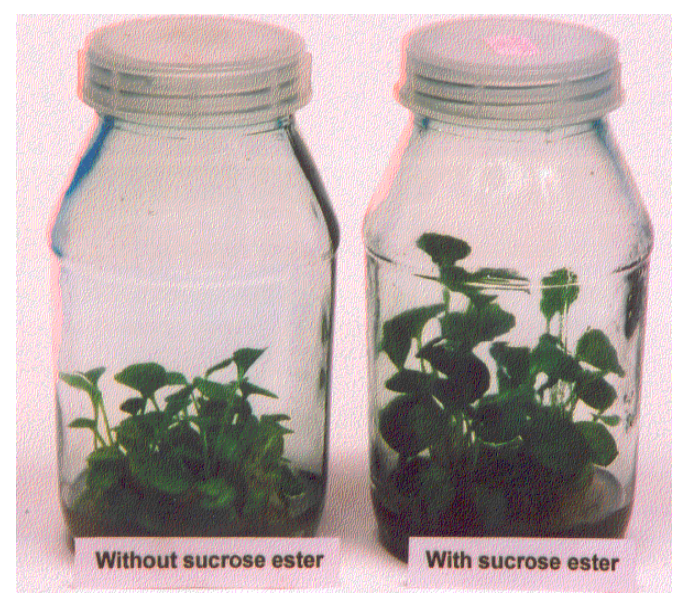

Fig. 1: Gerbera in media with and without sucrose ester.

During this investigation shoot formation was highly influenced by concentrations of sucrose ester in medium. 
The results presented in above Table 1 shows that the number of shoots and height of the shoots was significantly increased with addition of S.E in culture medium. The presence of sucrose ester in culture medium positively influenced the tissue culture of gerbera the number of shoots and height of shoots was significantly increased as the concentration of SE increased from $0.012 \%$ to $0.025 \%$.

Table 1. Effect of sucrose ester on tissue culture of gerbera

\begin{tabular}{llll}
\hline S. No. & Treatment $(\%$ S.E. in media) & Number of shoots per explant & Height of longest shoot \\
\hline T1 & 0 & $7.10 \pm 0.14$ & $3.20 \pm 0.04$ \\
T2 & 0.012 & $8.73 \pm 0.17$ & $4.13 \pm 0.05$ \\
T3 & 0.025 & $9.58 \pm 0.17$ & $5.05 \pm 0.02$ \\
T4 & 0.05 & $8.92 \pm 0.11$ & $4.17 \pm 0.02$ \\
T5 & 0.1 & $8.40 \pm 0.03$ & $4.01 \pm 0.02$ \\
T6 & 0.2 & $7.73 \pm 0.13$ & $3.82 \pm 0.07$ \\
T7 & 0.5 & $7.62 \pm 0.08$ & $3.42 \pm 0.06$ \\
S.E. & & 0.14 & 0.05 \\
\hline
\end{tabular}

All the values are the sum of means \pm SD of three parallel replicates.

Among different concentrations for shoot multiplication, best performance was showed on medium supplemented with $0.025 \%$ sucrose ester. Average number of shoots per explants was higher on this medium (9.58) with average height of longest shoot $5.05 \pm 0.02$. However, the number of shoots and height of shoot was significantly reduced when $\mathrm{S}$. E. concentration in media was further increased (0.05 to $0.5 \%)$. This indicates upper limit of SE concentration in tissue culture medium of gerbera.

\section{Conflict of interest statement}

Author declares that there is no conflict of interest.

\section{Acknowledgement}

The author is thankful to The Director General, Vasantdada Sugar Institute, Pune for providing the necessary facilities to carry out research work.

\section{References}

Aktar, N., Hoque, M.I., Sarker, R.H., 2012. In vitro propagation in three varieties of gerbera (Gerbera jamesonii Bolus.) from flower bud and flower stalk explants. Plant Tissue Cult. Biotech. 22(2), 143-152.

Altaf, N., Khan, A.R., Ali, L., Bhatti, I.A., 2009. Tissue culture of gerbera. Pak. J. Bot. 41(1), 7-10.

Anarjan, N., Tan, C.P., 2013. Effects of selected polysorbate and sucrose ester emulsifiers on the physicochemical properties of Astaxanthin Nanodispersions, Molecules. 18, 768-777.
Aswath, C., Wazneen, S., 2004. An improved method for in vitro propagation of Gerbera. J. Ornament. Hort. 7, 141-146.

Aswath, C.R., Choudhary, M.L., 2002. Rapid plant regeneration from Gerbera jamesonii Bolus callus cultures. Acta Bot. Croat. 61(2), 125-134.

Cristian, H.I., Candal, R.J., Herrera, M.L., 2009. Effects of addition of a palmitic sucrose ester on low-trans-fat blends crystallization in bulk and in oil-in-water emulsions. LNLS Activity Report, Brazilian Synchrotron Light Laboratory, 12.

Eid, A.M., Elnattah, N., Mahgoubi, A., Hamid, M.A., Hasham, R., Aziz, A., Ariffin, F.D., Salma, M.M, Elmarzugi, N.A., 2015. Usage of sugar ester in the preparation of Avocado oil nanoemulsion. Asian J. Pharm. Clin. Res. 8(4), 66-69.

Huang, M.C., Chu, C. Y., 1985. A scheme for commercial multiplication of Gerbera hybrid through shoot tip culture. J. Japan. Soc. Hort. Sci. 54(1), 94-100.

Kis, L., Szuts, A., Otomo, Szabo-Revesz, P., Deli, M.A., 2010. The Potential of sucrose esters to be used as oral absorption enhancers, Scientia Pharmaceutica Conference abstract, p.716.

Masoud, E.A.M., Haji, B. S., Mohammad, A.O., 2012. The influence of sucrose ester surfactant and different storage condition on the preparation of novel Swietenia macrophylla oil nano-emulsion. Int. Res. J. Pharm. 3(6), 199-207.

Plat, T., Linhardt, R.J., 2001. Syntheses and applications of sucrose-based esters. J. Surfact. Deterg. 4, 415-421.

Tyagi, P., Kothari, S.L., 2004. Rapid in vitro regeneration of Gerbera jamesonii (H. Bolus ex Hook. f.) from different explants. Ind. J. Biotech. 3, 584-588.

Zeng J., Gao, H., Guang, L.L., 2013. Effect of sucrose esters on the physicochemical properties of wheat starch, Trop. J. Pharmaceut. Res. 12(5), 685-690.

\section{How to cite this article:}

Salokhe, S., 2016. Study on applicability of sucrose ester in tissue culture media. Int. J. Curr. Res. Biosci. Plant Biol. 3(9), 132-134. doi: http://dx.doi.org/10.20546/ijcrbp.2016.309.016 